Original Research Paper

\title{
Humoral and Cellular Effects of Stress-An Extensive Model System
}

\author{
Mazal Shimon-Hophy and Ramy R. Avtalion \\ Lab of Comparative Immunology and Genetics, \\ Department of Life Science, Bar-Ilan University, Ramat Gan, Israel
}

\author{
Article history \\ Received: 19-12-2016 \\ Revised: 04-02-2017 \\ Accepted: 18-04-2017 \\ Corresponding Author: \\ Mazal Shimon-Hophy \\ Lab of Comparative \\ Immunology and Genetics, \\ Department of Life Science, \\ Bar-Ilan University, Ramat \\ Gan, Israel \\ Tel: 972-3-5318834 \\ Fax: 97239222202 \\ Email: hophymazal@gmail.com
}

\begin{abstract}
The influence of stress on the immune system of the common carp (Cyprinus carpio) was studied by measuring leukocytes levels using flow cytometry and mRNA immune components by real time qPCR. Acute and chronic oxidative stresses were generated by different regimes of exposure of carp to environmental air. In acute stress, induced by single air exposure, the pro-inflammatory cytokines (IL1 $\beta$, IL6 and TNF $\alpha$ ) and the down-regulatory ones (IL10 and TGF $\beta$ ) showed significant simultaneous elevations $(515,147,373,300$ and 198\% respectively). Following chronic stress (multiple air exposures) however, a drastic decline of $80 \%$, in macrophages/monocytes, B-cells likes and plasma-cells like, occurred in peripheral blood. No statistical changes in IL6 and TNF $\alpha$, as well as in IgM and $\mathrm{C} 3 \mathrm{~s}$ mRNA levels could be shown during this experiment. CD4 mRNA decreased up to $6 \%$ in the 2 nd week of chronic stress and elevated only to $55 \%$ at the 3rd week Vs a temporal decline of up to $22 \%$ in CD8a mRNA at the 2 nd week. The regulatory cytokines (IL10, FoxP3 and TGF $\beta$ ) as well as the pro-inflammatory ones (IL1 $\beta$ and IL17) decreased significantly up to $0.06,0.2,5,6$ and $4 \%$ respectively, at the second week before being restored to normal at the $3 \mathrm{rd}$ week. Moreover, a persistent decrease, up to null levels, in the cytokines IFN $\gamma 2 \mathrm{~b}$, IL12b and IL8 was also revealed. These downregulations were suggested as a result of the impaired Th1 and/or cytotoxic cell function and, to a certain degree, the leukocytes mobilization. The above findings show that in contrast to the detrimental effects of chronic stress, in which cells and functions of acquired immunity were partially or completely impaired, the acute stress was found rather beneficial and in line with the known ephemeral "fight and flight" response.
\end{abstract}

Keywords: Chronic Stress, Acute Stress, Fish, Leukocyte, Cytokines

\section{Introduction}

Fish under intensive culture conditions are often exposed to a variety of acute and chronic stressors. These include: Elevated rearing densities (Vazzana et al., 2002), suboptimal water quality, decreased dissolved oxygen and elevated carbon dioxide $\left(\mathrm{CO}_{2}\right)$ levels (Franco et al., 2009; Lefèvre et al., 2008), thermal fluctuations (Zarate and Bradley, 2003; Avtalion, 1969; 1981; Avtalion et al., 1976; Varsamos et al., 2006), diet (Montero et al., 1999; Montero et al., 2001; Costas et al., 2011), presence of enemies and pathogens (Demers and Bayne, 1997; Sunyer and Tort, 1995; Saeij et al., 2003), transportation and sorting, handling and confinement stresses (Costas et al., 2011; Harmon 2009; Maule and Schreck, 1991; Noga et al., 1999). Stressors have negative impacts on different physiological responses associated with growth, nutrition, reproduction and immune responses (Lefèvre et al., 2008; Zarate and Bradley, 2003; Øverli et al., 2006; WendelaarBonga, 1997; Campbell et al., 1992; Poli et al., 2005; Pickering 1992; Olsen et al., 2005; Hoskonen and Pirhonen, 2006; Vargas-Chacoff et al., 2001). Understanding and monitoring the biological mechanisms underlying stress responses in fish may alleviate their negative effects through selective breeding and changes in management practices, resulting in improved animal welfare and production efficiency. This might also 
provide further understanding of stress mechanisms involved in higher vertebrates.

Stressors were reported to exaggerate adverse effects like sensitivity to illness, autoimmunity, shrinking of the thymus and spleen or other lymphatic organs, changes in the number and distribution of white blood cells, or appearance of bleeding or ulcers (Harper and Wolf, 2009). Stress increases immunosuppressive pathways and increases proinflammatory cytokines (Tort et al., 1996; Douxfils et al., 2011; Milla et al., 2010; Talbot et al., 2009; Petrovsky, 2001). These stress effects impact both the innate and adaptive immune system (Øverli et al., 2006; Mommsen et al., 1999), mainly following considerable decrease in lymphocyte numbers (Engelsma et al., 2003), plasma IgM concentration (Nagae et al., 1994), a selective suppression in phagocytosis and complement activities in head kidney and blood. As a consequence, an increase in susceptibility to infection occurs in teleost fish (Pickering, 1984; Law et al., 2001; Small and Bilodeau, 2005; Mauri et al., 2011).

The effect of stress depends on the duration and intensity of the stressor. Mild and/or acute stressors enhance immune responses while, severe or long-term stressors can be immunosuppressive (Demers and Bayne, 1997; Sunyer and Tort, 1995; Harris and Bird, 2000; Raberg et al., 1998). In handling acute stress, an increase in C3, lysozymes (Demers and Bayne, 1997; Sunyer and Tort, 1995) and leukocytes (Maule and Schreck, 1991) were reported in head kidney. In chronic stress however, there is a decrease in C3 and lysozyme levels (Sunyer and Tort, 1995) as well as in immune cell numbers and functions (Verburg-Van Kemenade et al., 2009). It was assumed that this dual response depends on the intensity and duration of the stressor and that these processes are controlled by different hormonal and neuronal paths (Tort, 2011; Nardocci et al., 2014).

The stress mechanism has been mostly studied in higher vertebrates and much less in fish. In mammals, immune and inflammatory responses are followed by the activation of the stress hormones that systemically inhibit the T-helper-1(Th1) pro-inflammatory responses but potentiate a Th2 shift which is followed by downregulation of some cytokines involved in cellular immunity (TNF- $\alpha$, IFN- $\gamma$, IL-2, IL-12) as well as production of cytokines belonging to other Th-cell subsets (IL-4, IL-10, IL-13, TGF- $\beta$ ) (Elenkov and Chrousos, 1999). Furthermore, it has been shown that stress induces changes in cell numbers and in their traffic patterns. Substantial differences in the leukocyte distribution in different body compartments have been observed in carp (Wojtaszek et al., 2002).

It was stated by these authors that such a situation may lead to ineffective immune protection due to decreased leukocyte recruitment at the affected sites. The activation of leukocytes is related to the activation of the sympathetic nervous system and to the release of catecholamines (Tort, 2011; Dhabhar, 2002). Blood cells, including both erythrocytes and leukocytes, are mobilized as part of the acute stress response. The changes in blood leukocyte numbers are characterized by a significant reduction in the numbers and percentages of lymphocytes and monocytes and by an increase in the numbers and percentages of neutrophils (Dhabhar, 2002).

Several studies in fish, support stress mechanism as reported in mammals (Wojtaszek et al., 2002; Dhabhar, 2002; Cortés et al., 2013), while the participating immune cells and humoral processes are still vague. Therefore, in the present work we describe the influence of air exposure acute and chronic stresses (Melamed et al., 1999; Dror et al., 2006) on different immune components of spleen, blood, kidney and head kidney in the common carp. Hence, we studied the participation of most of the known components in the fish immune system in acute and chronic stresses by examining changes in the levels of: (1) Immune cell groups of small and large lymphocytes, Polymorphonuclear (PMN) cells and monocytes/macrophages during stress treatments; (2) CD4 and CD8a cells which represent the majority of cells involved in immune processes (Todaa et al., 2011; Annunziato and Romagnani, 2009; Wan and Flavell, 2009); (3) IgM and the complement C3s (a fish variant of mammal C3) which are considered as significant agents of the innate immunity (Nakao et al., 2000; Brattgjerd and Evensen, 1996; Kaattari and Irwin, 1985); (4) The pro-inflammatory cytokines IL1b, IL6 and TNFa (Secombes and Fletcher, 1992); (5) the inflammatory cytokines related to Th1 cells (IFN $\gamma 2 \mathrm{~b}$ and IL12b) and Th17 cells (IL17) (Du et al., 2014; Zou et al., 2005; Wang et al., 2014); (6) IL10, TGF $\beta$ and FoxP3 (Wei et al., 2013; Wang et al., 2010; Kohli et al., 2003) regulatory cells cytokines; (7) The chemoattractant CXCL8 that acts similarly to the mammalian IL8 in mobilizing macrophages/neutrophils/leukocytes to the target area (Van der Aa et al., 2012).

\section{Materials and Methods}

\section{Animals}

Common carp (150 \pm 30 gr.) were obtained from a local fish farm (Mishmar Hasharon, Israel). The fish were acclimatized to laboratory conditions for at least one month before experiments. Fish were maintained in containers $(105 \times 105 \times 80 \mathrm{~cm})$ with air bobbling and recirculating fresh water at $24 \pm 2{ }^{\circ} \mathrm{C}$, in a $12 \mathrm{~h}$. light $/ 12$ h. Dark cycle and fed a commercial diet once a day. Two weeks before the experiment, the fish were kept into net cages $(75 \times 28 \times 48 \mathrm{~cm}), 2$ fish in each one. The 
cages were maintained in water tanks $(350 \times 300 \times 100$ $\mathrm{cm})$, equipped with a biological filter and continuous flow of water and air.

\section{Acute Stress}

A group of 8 fish was exposed for $10 \mathrm{~min}$. to the air and then immersed for $30 \mathrm{~min}$. in water, after three cycles of exposure/immersion, the fish were left for $24 \mathrm{~h}$ in the water (Melamed et al., 1999; Dror et al., 2006) and then anaesthetized by immersion in $0.01 \%$ benzocaine/water. Their spleens were collected into liquid Nitrogen for RNA extraction. In order to minimize handling stress, all stress treatments were done into the net cages i.e., the net with the fish was exposed to the air and immersed into the water.

\section{Chronic Stress}

The fish were similarly treated as in the acute stress group, but the exposures to the air and immersions, as above, were repeated three times a week for three weeks. Twenty four hours following the last air exposure, performed at the 9th, 16th and 23th days, groups of 8 fish each were anaesthetized by immersion in a $0.01 \%$ benzocaine solution and their spleens were collected into liquid Nitrogen for RNA extraction.

\section{Gene Expression Quantification}

Total RNA was extracted from each spleen using $1 \mathrm{ml}$ TRI reagent according to the manufacturer's instructions (Geneall Biotechnology, Seoul, Korea). RNA quantification was carried out using a NanoDrop ND2000c spectrophotometer (Thermo Scientific). Total RNA quality was monitored by running samples on a $1.3 \%$ agarose gel. Adequate samples were used for complementary DNA (cDNA) synthesis which was carried out with the FastQuant RT Kit (with gDNase) (Tiangen, Beijing, China) and served as a negative control for quantitative PCR (qPCR). Part of the cDNA was used for a standard curve in each qPCR experiment and the rest of the material was diluted to $100 \mathrm{ng} \mu \mathrm{L}^{-1}$. qPCR amplification was carried out in $20 \mu \mathrm{L}$ reaction volume containing $5 \mu \mathrm{L}$ of diluted cDNA (500 ng) used as a template for qPCR cytokine quantification, $10 \mu \mathrm{L}$ FastFire qPCR PreMix (Syber Green) (Tiangen, Beijing, China) and $5 \mu \mathrm{L}$ primer, resulting in a final concentration of $0.1 \mu \mathrm{M}$.

All immune component samples were run in triplicate while standards (standard curve of each cytokine and of the RNA negative control following gDNase) in duplicate in the CFX96 (Bio Rad) following the manufacturer's conditions, as follows: Initial denaturation for $1 \mathrm{~min}, 95^{\circ} \mathrm{C}$, followed by 40 cycles of 5 sec denaturation at $95^{\circ} \mathrm{C}$ and $15 \mathrm{sec}$ for annealing/extension at $59^{\circ} \mathrm{C}$ to $62^{\circ} \mathrm{C}$ (Table 1). The melting curve in each experiment was used to examine qPCR and primer quality. Results of qPCR experiment were accepted if: (1) There was no contamination of dimmers or other material; (2) the efficiency of the qPCR reaction was 90 to $109 \%$, (3) the R line of the reaction was 0.98 to 1 .

\section{PCR Qualification}

Amplification was performed in a $20 \mu \mathrm{L}$ of a reaction volume containing $10 \mu \mathrm{L}$ GoTaq Green Master Mix (Promega, Madison, WI, USA), $5 \mu \mathrm{L}$ primer (in a final concentration of $0.1 \mu \mathrm{M}$ ) and $5 \mu \mathrm{L}$ diluted cDNA (500 ng). This solution was used as a template to synthesize immune components in each stress treatment. Samples were run in the UNO II (Biometric) as follows: Initial denaturation for $5 \mathrm{~min}$ at $95^{\circ} \mathrm{C}$, followed by 30 cycles of $30 \mathrm{sec}$ denaturation in $95^{\circ} \mathrm{C}, 30 \mathrm{sec}$ annealing at $60^{\circ} \mathrm{C}$ and $30 \mathrm{sec}$. extension at $72^{\circ} \mathrm{C}$, ending with $72^{\circ} \mathrm{C}$ for $10 \mathrm{~min}$. Samples were loaded on an $1.3 \%$ agarose gel and visualized by a MiniLumi Imaging System (DNR Bio Imaging Systems).

\section{Primer Design}

Primers were designed by the NCBI tool and purchased from Integrated DNA Technologies, Leuven, Belgium (IDT). Each primer was analyzed by an IDT Oligo Analyzer. Running conditions of each primer were analyzed and only those which showed negligible dimmer, high PCR efficiency (90-109\%) and $\mathrm{R} \geq 0.98$. were used (Table 1).

\section{Data Analysis}

All experiments were analyzed by the CFX96 (Bio-Rad) software. Ratio production of immune components between stress conditions to control was expressed as fold changes. $\mathrm{Cq}$ was normalized to gene reference $40 \mathrm{~S}$ rRNA and analyzed according to the Pfaffl and Livak method (Pfaffl, 2001; Livak and Schmittgen, 2008) by correcting the efficiency of each primer at stress relative to control.

\section{Cell Separation}

About $1 \mathrm{~mL}$ blood was removed from the caudal vein of each fish by a heparinized syringe and diluted in $9 \mathrm{~mL}$ Dulbecco's Modified Eagle Medium (DMEM) solution (Biological Industries, Israel). The spleens, kidneys and head kidneys of six fish from each treatment were removed following anesthesia from the groups of control, unstressed, acutely stressed and chronically stressed fish after one, two and three weeks. Organs were minced through a net with a $10 \mathrm{~mL}$ syringe piston into DMEM solution. Leukocytes were separated on FicollPaque $^{\mathrm{TM}}$ plus (GE Healthcare). After three washes, cells were used for Flow Cytometry (FACS) and for MayGrunwald/Gimsa/right staining and identification. 
Table 1. Primers for immune components and their annealing/extension temperature in the PCR and RT-qPCR reaction

\begin{tabular}{|c|c|c|c|c|c|}
\hline Cytokine & & $\begin{array}{l}\text { Product } \\
\text { Lenth }\end{array}$ & AET* & Reverse & Forward \\
\hline IL1 $\beta$ & AB010701.1 & 98 & 62 & TGGCAACTCATGGATTGTGGA & GATTTGTCAGAAGCATTCGAGAC \\
\hline IL6 & AY102632.1 & 96 & 60 & AGCTGGCTGCAAGTTTCGT & AGCTAAATTCAGAATGATCCTCGCT \\
\hline IL8 & AB470924.1 & 137 & 60 & TTGGCTCTTGAGGTTCCTCTTTT & TTATTCCTGCTGGACCAATTTGC \\
\hline IL10 & AB110780.1 & 94 & 60 & АССТТТТТССТТСАТСТТTТСАТАСGА & GGATATGCGGAAATGTAGGAATTAC \\
\hline IL12b & AJ628699. & 102 & 60 & GCAGCGATACCTCAAAGCTG & AAGCTGTCCTTCAGTTGGCA \\
\hline IL17A/F2 & HM231140.1 & 82 & 60 & GGC AGT GAG TTCAGT CTC GTA & CGC AGG TCATCTTTGAAGCCCA \\
\hline INF $2 \mathrm{~b}$ & JX181980.1 & 120 & 62 & TGTGCCAGTTTTTCTTTTGTAGC & AGACATAAAGGAACCTGAGCAGAA \\
\hline $\mathrm{TNF} \alpha$ & $\mathrm{AJ} 311801.2$ & 111 & 60 & TGTAGCTGCCGTAGGACTCAG & ACAGCCAGGTGTCTTTCCAC \\
\hline $\mathrm{C} 3 \mathrm{~s}$ & AB016213.1 & 94 & 60 & CTGACTGCCCACCACTTCTA & CAAACCTGGAATGCCCTTCG \\
\hline IgM & AB004105.1 & 101 & 62 & CAGCAAGCCAAGACACAAACA & CGTATTAGCACCCCCAGAGC \\
\hline FoxP3 & AB741577.1 & 71 & 59 & TGACTTCCCCACACTGTTACCAT & TACAGGCTATGCAGCTACACC \\
\hline $\mathrm{TGFb}$ & AF136947.1 & 120 & 60 & CACAGTTATCCGCCATCTTC & CACGCTTTATTCCCAACCA \\
\hline $\mathrm{CD} 4$ & DQ400124.1 & 111 & 60 & CAGGGATGGACAGAGAAGAT & GCACACTAGGACATCAACATAG \\
\hline CD8a & EU251078.1 & 96 & 59 & GTTGCTGGATCAGGTTCTC & GACAGACAGTGGTTTCTACAC \\
\hline $40 \mathrm{~S}$ & AB012087 & 83 & 60 & TCCTTCAACAGCGAGAACCC & TGGCGGACATACAGAACGAGAG \\
\hline
\end{tabular}

$\mathrm{AET}^{*}$, annealing/extension temperature

\section{FACS}

Cells were incubated in PBS solution containing monoclonal mouse anti carp IgG (produced in our lab), $0.1 \%$ sodium azide and $2 \%$ Bovine Serum Albumin (BSA) (Sigma) for $30 \mathrm{~min}$ at $4^{\circ} \mathrm{C}$, were washed twice and incubated in PBS with FITC-goat anti mouse $\operatorname{IgG}$ (Sigma) for $30 \mathrm{~min}$ at $4{ }^{\circ} \mathrm{C}$, were washed twice and kept in a PBS solution containing $0.1 \%$ sodium azide, $2 \% \quad$ BSA and $0.6 \%$ paraformaldehyde, at $4{ }^{\circ} \mathrm{C}$. Cell analysis was performed on a flow cytometer, FACSCalibur (Becton Dickinson) equipped with a $488 \mathrm{~nm}$ cooled argon-ion laser. Green fluorescence was collected through a 520-530 nm bandpass filter. About 30,000 cells within the gated region were identified. Results were analyzed by the FlowJo software (FlowJo, LLC, Ashland, Or, USA).

\section{Cell Staining}

Slides were stained as follows: (1) Fixed for $3 \mathrm{~min}$ in methanol and dried by air; (2) Immersed for $20 \mathrm{~min}$ in diluted May-Grunwald solution (Sigma) $(1: 1$ in methanol), then were washed for $1 \mathrm{~min}$ in phosphate buffer $\mathrm{pH}$ 6.3, $0.01 \mathrm{M}$ (PB) and dried by air; (3) Immersed for $30 \mathrm{~min}$ in diluted Giemsa stain (Sigma) $1: 3$ in PB and then were washed for 6 min in PB and dried by air; (4) Immersed in Wright stain (Sigma) $200 \mathrm{mg} / 40 \mathrm{~mL}$ methanol for $20 \mathrm{~min}$ and then washed for $15 \mathrm{~min}$ in PB. Cells were observed and counted by axioimager.Z1 microscope (Zeiss).

\section{Follow-up of Blood Leukocyte Profile in Stressed Fish}

We used a group of 4 fish to follow changes in their individual peripheral blood leukocyte profiles throughout the stress treatments. Therefore, blood control samples ( $1 \mathrm{~mL}$ each) were taken from the caudal vein of each fish, with heparinized syringe, before stress treatments. Two weeks later, the fish were treated for acute stress, as detailed above and $24 \mathrm{~h}$ later, blood samples were taken, as above, from each fish. Two weeks later, the fish were treated for chronic stress during 3 weeks, as detailed above and blood samples were taken at the end of each week. Leukocytes from each blood sample were then separated on a Ficoll gradient and used for FACS evaluation and for cell staining as detailed above.

\section{FACS-Determination of Cell Groups}

Blood samples of 3 fish were taken as above and leukocytes were separated on Ficoll gradient. Leukocytes sorted by FACS ARIA III (BD Bioscience) to 4 main FACS gated groups (Fig. 1). Cell sample of each leukocytes group was transferred to slides by cytocentrifugation (Elliot-Shandon, Recyclab), stained as above for microscopy and FACS identification of each gated group.

\section{Identification of Macrophages/Neutrophils}

Leukocytes were incubated in a solution of $200 \mu \mathrm{L}$ PBS containing 2\% Hepes, $0.2 \%$ BSA, $10^{7}$ FITCStaphylococcus albus and $50 \mu \mathrm{L}$ carp inactivated serum, for $1 \mathrm{~h}$ at $28^{\circ} \mathrm{C}$. The reaction was stopped by adding cold PBS. Fluorescence of phagocytosing cells in the analyzed gates in flow cytometry was examined by FACSCalibur (Becton Dickinson) and ImageStream (Merck Millipore).

\section{Statistical Analysis}

The acute stress results were tested for significance by $\mathrm{F}$ and $\mathrm{T}$ tests and those of chronic stress were analyzed by a one way ANOVA followed by Bonferroni and Tamhane Post Hoc Tests. 


\section{Results}

Cell sorting and staining of the different cell groups showed that: Cells of group A consisted mostly in small lymphocytes; of group B in medium and large lymphocytes; of group C in PMN cells and of group D in macrophages/monocytes (Fig. 1). Neutrophils and macrophages were identified by phagocytosis of marked Staphylococcus albus, flow cytometry and cell staining. B-cell like and plasma-cell like were identified by staining with FITC-bounded monoclonal mouse anti carp IgG and fluorescence examination using FACSCalibur and ImageStream. Leukocyte levels showed high variability between individuals which disguised stress influence (Fig. 2). Consequently, the influence of stress was also studied by following changes in peripheral blood leukocyte levels in 4 carp throughout different stress treatments (Table 2). In acute stress, only the follow up of peripheral blood leukocytes levels showed a significant decrease in small lymphocytes and B-like cells $(\sim 10 \%$, $\sim 50 \%$ respectively) ( $\leq 0.05$ ) (Table 2 ). In chronic stress, by sampling 8 carps, leukocyte levels throughout stress treatments did not show significant changes in ANOVA test in the kidney and the head kidney except a decrease of $15 \%$ of B-cell like at the $3^{\text {rd }}$ week of chronic stress in the kidney. On the other hand, in the spleen and the blood, macrophages/monocytes decreased significantly up to $50 \%$ in the blood by one way ANOVA test and in the spleen by trend test. Moreover, B-cell-like and plasmacell like decreased significantly, as evaluated by trend test, up to $50 \%$ in the blood $(\mathrm{p} \leq 0.05)$ (Fig 2). Moreover, trend test indicated that PMN cells levels rose slightly and permanently during weeks 1-3 of chronic stress $(\mathrm{R}=0.998)$ in head kidney (Fig. 2). On the other hand, by following changes in leukocyte profiles of peripheral bloods of 4 individuals throughout stress treatments resulted in a drastic decline of $70-80 \%$ of macrophages ( $\mathrm{p} \leq 0.05$, in one way ANOVA) (table 2). In a similar way, B-like lymphocytes and plasma-like cell levels, decreased significantly by $80 \%$ in the blood (Table 2) at week 2 and 3 of chronic stress ( $\mathrm{p} \leq 0.05$, in one way ANOVA test).
Results of immune components revealed that in acute stress, the level of the proinflammatory cytokines, IL1 $\beta$, IL6 and TNF $\alpha$, showed a significant increase of $515 \%, 147 \%, 373 \%$ Vs control, respectively $(p \leq 0.05)$, as well as that of the down-regulatory ones, IL10 and TGF $\beta$, that showed a significant increase by 300 and 198\%, respectively (Table 3 and Fig. 3, first and second wells). The level of the other components mRNAs: IL8, IgM, IFN $\gamma 2$ b, FoxP3, C3s and the cell markers CD4 and $\mathrm{CD} 8 \alpha$, showed no significant changes, except a slight insignificant decrease in $\mathrm{C} 3 \mathrm{~s}$ mRNA (Table 3 and Fig. 3, well 2).

In chronic stress, cytokine mRNA levels of IL6, $\mathrm{TNF} \alpha, \mathrm{C} 3 \mathrm{~s}$ and IgM showed no significant changes compared to the control throughout the whole treatments (Fig. 4A and 4D) in spite of some fluctuations were seen especially in C3s levels (Fig. 3). IL1 $\beta$, TGF $\beta$ and CD8a mRNA decreased respectively to $6 \%, 5 \%$ and $22 \%$ levels of control at the second week, after 7 regimes of stress. At the third week, however, after 10 regimes of stress, they returned to control levels (Fig. 4A, 4E and 4C), except IL1 $\beta$ which increased by 2.7 times above the control level $(p \leq 0.05)$ at returning to homeostasis. IL12b, IFN $\gamma 2 \mathrm{~b}$ mRNA decreased dramatically to zero levels throughout the whole chronic stress time and their levels did not recover even after three weeks of stress (Fig. 4B). IL8 and CD4 mRNA alike IL12b and IFN $\gamma 2 \mathrm{~b}$ considerably decreased at the first week up to 1 and $6 \%$ and rose to $25 \%, 55 \%$ levels of the control, respectively, at the third week (Fig. 4A and 4C). IL10 and FoxP3 mRNA decreased sharply $(\mathrm{p} \leq 0.05)$ in the second week to the level of 0.06 and $0.2 \%$ of the control, respectively. In the third week of chronic stress, after 10 regimes of air exposure, their mRNA amounts returned to control levels (Fig 4E). It is noteworthy that the evaluation of IL17mRNA was quantified by PCR instead of real time qPCR because of difficulties in selecting proper primers. IL17 mRNA decreased following acute stress to $4 \%$ and at the first week of chronic stress to almost zero levels. However, its levels rose from the second week, reaching control levels in the third week of chronic stress (Fig. 3).

Table 2. Leukocyte percentages in common carp peripheral blood following stress treatments

\begin{tabular}{lllllll}
\hline & $\begin{array}{l}\text { Small } \\
\text { lymphocyte }\end{array}$ & $\begin{array}{l}\text { Large } \\
\text { lymphocyte }\end{array}$ & $\begin{array}{l}\text { Monocytes/ } \\
\text { Macrophage }\end{array}$ & PMN cells & B cells like & $\begin{array}{l}\text { Plasma cell } \\
\text { like }\end{array}$ \\
\hline ctrl & $70.07 \pm 3.03$ & $14.98 \pm 1.77$ & $1.05 \pm 0.09$ & $3.35 \pm 0.89$ & $8.50 \pm 1.69$ & $4.86 \pm 2.52$ \\
as & $62.85 \pm 3.95^{*}$ & $13.36 \pm 2.13$ & $1.01 \pm 0.32$ & $8.84 \pm 2.49$ & $4.28 \pm 0.95^{*}$ & $3.76 \pm 0.76$ \\
csw1 & $67.73 \pm 4.22$ & $14.43 \pm 2.2$ & $0.30 \pm 0.06^{*}$ & $3.27 \pm 1.27$ & $3.86 \pm 1.40$ & $2.54 \pm 0.70$ \\
csw2 & $71.25 \pm 5.90$ & $11.32 \pm 2.47$ & $0.26 \pm 0.09^{*}$ & $1.90 \pm 0.81$ & $1.34 \pm 0.37^{*}$ & $1.64 \pm 0.42^{*}$ \\
csw3 & $68.67 \pm 6.85$ & $9.93 \pm 3.16$ & $0.21 \pm 0.05^{*}$ & $4.77 \pm 0.69$ & $1.38 \pm 0.17^{*}$ & $0.93 \pm 0.25^{*}$ \\
\hline
\end{tabular}

$*, p \leq 0.05$ in one way ANOVA. Each result was the mean of 4 followed individual fish \pm SEM. The results represented changes in the percent of leukocytes following five different stress treatments. The cell percentage was calculated from 30000 cells identified by FACSCalibur in the gated area and analyzed by the FlowJo software. Cell type was identified by cell sorting, binding of monoclonal mouse anti carp IgG to leukocytes, phagocytosing FITC-Staphylococcus albus and by cell staining. ctrl, control; as, acute stress; csw1, one week of chronic stress; csw2, two weeks of chronic stress; csw3, three weeks of chronic stress. 


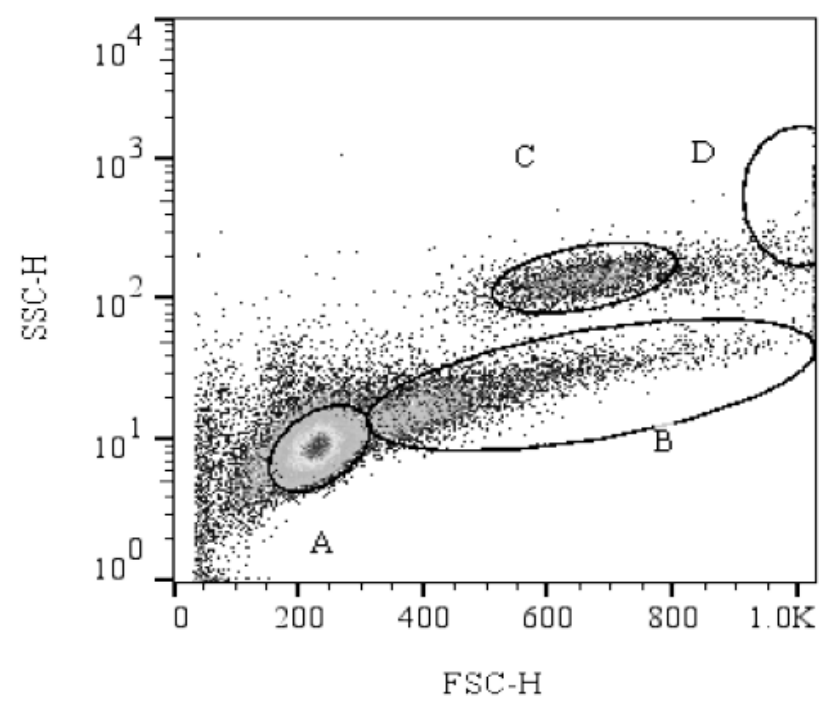

Fig. 1. Four main leukocytes groups A, B, C and D were sorted by FACS and then the sorted samples were cytocentrifuged on slides, fixed by methanol and stained with MayGrunwald/Giemsa/Wright stains. Cell classification was performed by microscopy (x100)

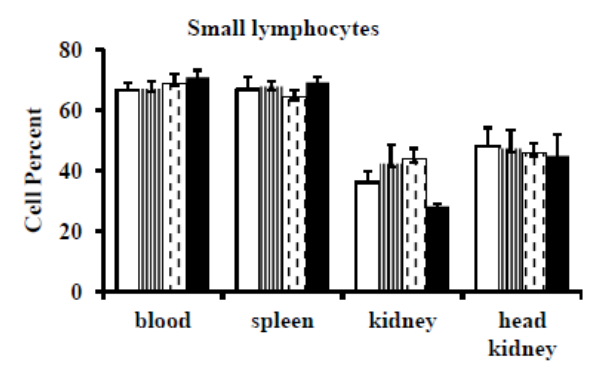

Macrophages/Monocytes
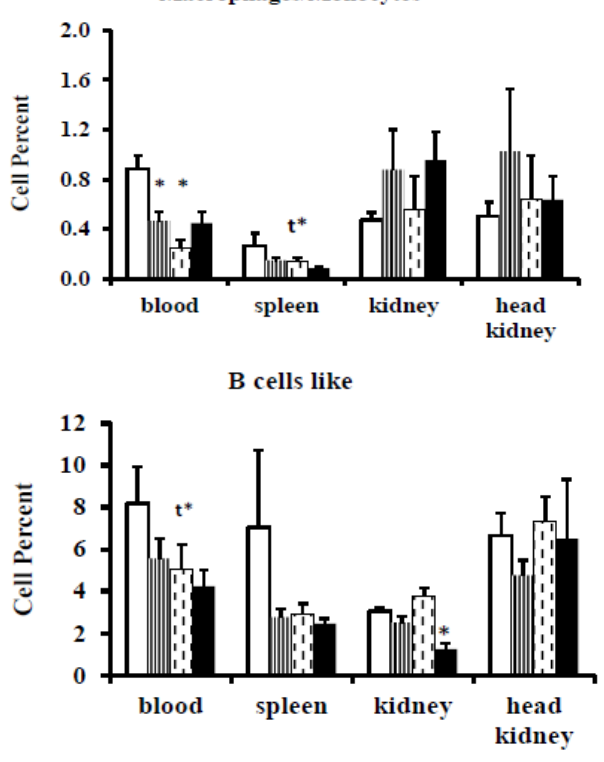
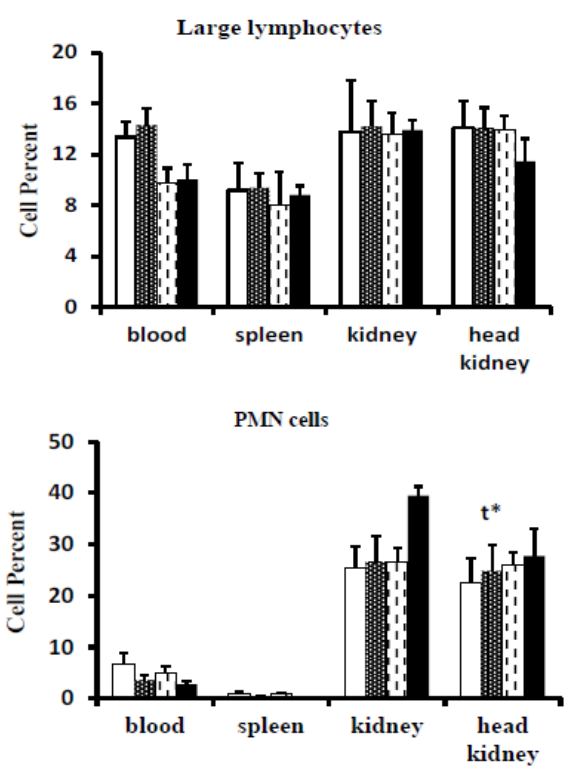

Plasma cells like

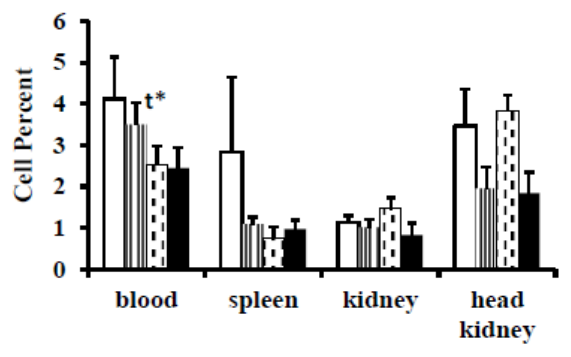

Fig. 2. Percent of leukocytes in carp lymphatic organs following chronic stress treatments: *, one way ANOVA $p \leq 0.05 ; t^{*}, a$ significant trend of elevation/decrease of cells $\leq 0.05$. The results represent the mean of 6-8 carp \pm SEM. Carp were treated in chronic stress along three weeks. At each week leukocytes from lymphatic organs were separated. Cell percent levels were calculated from 30000 cells identified at the gated area by FACSCalibur and analyzed by the FlowJo software. ctrl, control; csw1, one week of chronic stress; csw2, two weeks of chronic stress; csw3, three weeks of stress 


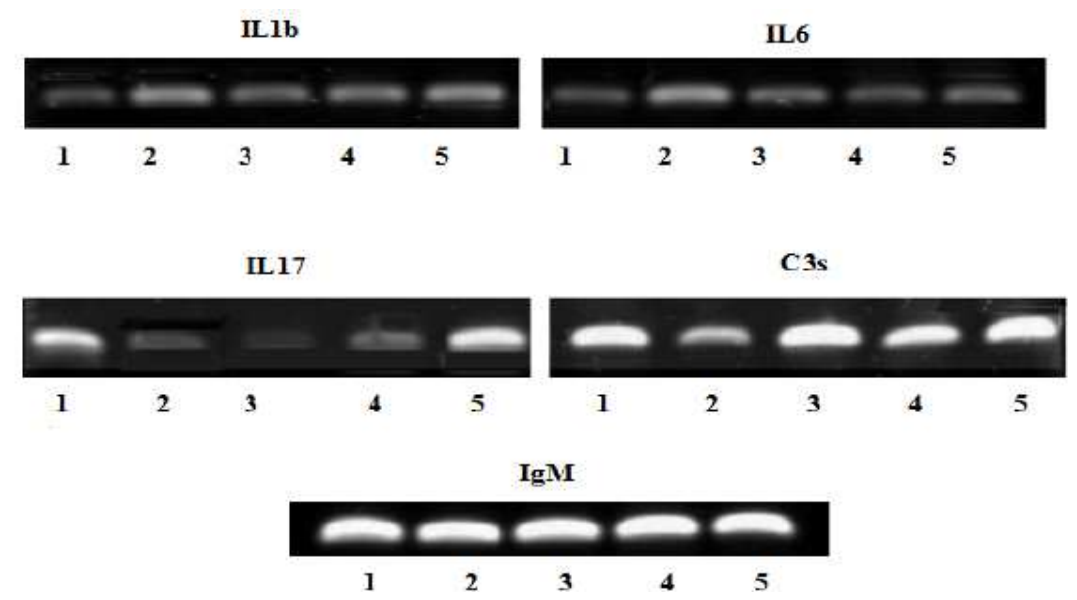

Fig. 3. Comparative cytokine levels in common carp spleen following different stress treatments. Cytokines were produced from mixed 500 ng cDNA of 8 fish by PCR amplification and loaded on 1.3\% agarose gel with TBE running solution. 1, control; 2, acute stress; 3 , one week of chronic stress; 4 , two weeks of chronic stress; 5 , three weeks of chronic stress
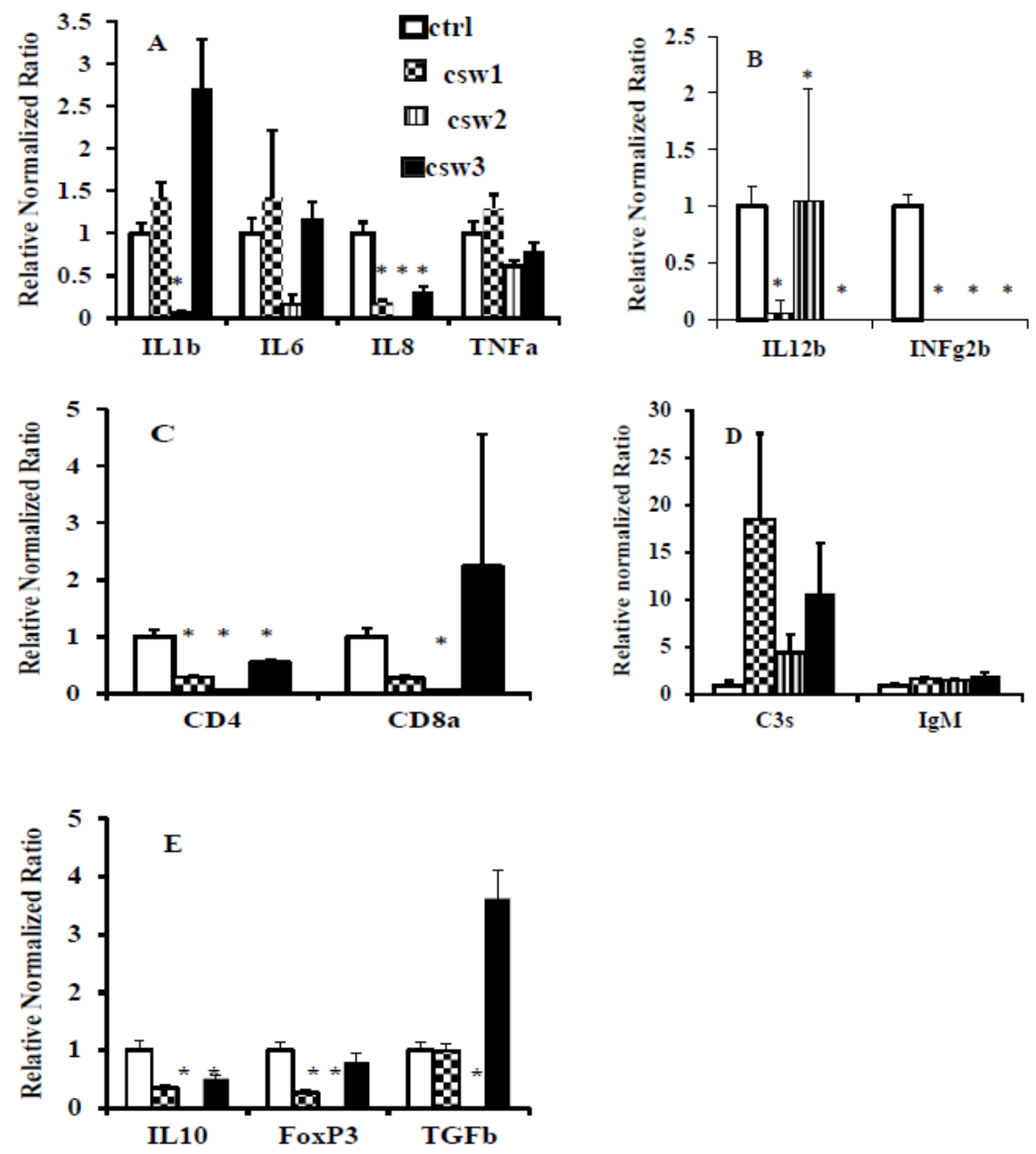

Fig. 4. Immune component levels during chronic stress. *, p $<0.05$ in one way ANOVA. Each result was a mean of 8 carp spleens \pm SEM, Component levels were measured by qPCR after three air exposure regimes per week. Results were normalized to $40 \mathrm{~S}$ rRNA and the component ratio to the control was calculated by the $\Delta \Delta \mathrm{Cq}$ method. ctrl, control fish; csw1, one week of chronic stress; csw2, two weeks of chronic stress; csw3, three weeks of chronic stress 
Table 3. Normalized ratio of carp spleen cytokines following acute stress induction

\begin{tabular}{|c|c|c|c|c|c|c|c|c|c|c|c|c|}
\hline & IL1b & IL6 & IL8 & IL10 & INF $\gamma 2 b$ & $\mathrm{TNFa}$ & $\mathrm{C} 3 \mathrm{~s}$ & IgM & FoxP3 & TGF $\beta$ & CD4 & CD8a \\
\hline ctrl & $1 \pm 0.12$ & $1 \pm 0.18$ & $1 \pm 0.13$ & $1 \pm 0.15$ & $1 \pm 0.12$ & $1 \pm 0.14$ & $1 \pm 0.8$ & $1 \pm 0.12$ & $1 \pm 0.14$ & $1 \pm 0.14$ & $1 \pm 0.12$ & $1 \pm 0.15$ \\
\hline as & $5.15 \pm 0.67 *$ & $1.47 \pm 0.28 *$ & $0.81 \pm 0.08$ & $3.01 \pm 0.34 *$ & $1.4 \pm 0.19$ & $3.73 \pm 0.27 *$ & $0.79 \pm 0.21$ & $1.35 \pm 0.16$ & $2.51 \pm 0.73$ & $1.98 \pm 0.21 *$ & $0.84 \pm 0.1$ & $1.3 \pm 0.18$ \\
\hline
\end{tabular}

\section{Discussion}

In the present study, we followed changes in leukocytes profiles of blood and lymphatic organs and measured levels of components representing the main functions of the immune system during acute and chronic stresses in order to further elucidate the involved cellular and molecular mechanisms. The spleen was used mainly to follow changes in immune constituents in the humoral system because preliminary experiments (data not shown) revealed that the cytokines level profile in the spleen was similar to that of the blood and provided more material for gene expression experiments than the blood. In addition, the leukocyte spread of spleen and peripheral blood displayed similar patterns, while that of kidney and head kidney were different. Whereas, the lymphocytes levels were higher than those of PMN cells in the peripheral blood and the spleen, the levels of both populations were almost similar in the kidney and the head kidney (Fig. 2).

In acute stress, our results are in agreement with previous studies (Barker et al., 1991; Banerjee and Leptin, 2014) showing significant increased levels of pro-inflammatory cytokines (IL1 $\beta$, IL6 and TNF $\alpha$ ), as well as of down-regulatory ones (IL10 and TGF $\beta$ ) (Table 3). It is possible that the joint elevation of these regulatory cytokines with that of the pro-inflammatory ones was involved in the shortened time of the proinflammatory response and the restoring of homeostasis. The pro-inflammatory cytokines are known to be involved in "fight or flight" response (Tort, 2011) in order to overcome ephemeral stressors.

The effect of stress on fish was widely variable between individuals. Consequently, the leukocyte averages in lymphatic organs were ambiguous (Fig. 2). Therefore, a follow up of changes in leukocyte levels of peripheral blood throughout stress treatments (Table 2) elicited the question of the sampling size, or of the research tool. As a result, following changes in leukocyte levels of peripheral blood were considered as a significant parameter.

In acute stress, the leukocytes levels showed significant changes only by following levels in peripheral blood. Lymphocytes decreased 10\% possibly due to the significant decrease of up to $50 \%$ in the B-cell like (Table 2).

In chronic stress, CD4 and CD8a mRNA levels decreased up to the second week $(\mathrm{p} \leq 0.05)$, but while
CD4 mRNA remained depressed towards the third week, CD8a mRNA returned to homeostasis (Fig. 4C). This may explain the drastic decrease of $80 \%$ of macrophages, B-cell like and plasma-cell like in peripheral blood (Table 2). These results were in agreement with the decrease in leukocyte numbers in Oncorhynchus mykiss (Cristea et al., 2012), suppression of phagocytic and lymphocyte proliferative activities in Platichthys flesus and Solea senegalensis (Pulsford et al., 1995) and apoptosis of B cells in Cyprinus carpio (Verburg-Van Kemenade et al., 1999). Nevertheless, IL12b and IFN $\gamma 2 \mathrm{~b}$ mRNA products (Fig. 4B) decreased to null throughout 22 days and their levels did not recover even after the third week of chronic stress. It was possible that this dramatic decrease was a result of the deleterious functions of producing IFN $\gamma 2 \mathrm{~b}$ and IL12b mRNA in CD4 cells, especially following the impairment of Th1 cells (Wojtaszek et al., 2002; Cristea et al., 2012). Production in Th1 cells alone can't explain the zero levels of IFN $\gamma 2 b$. Therefore, it is suggested that additional impaired cell types like NK cells, might be involved because of the partial decline in CD8a mRNA. The sharp decrease in IFN $\gamma 2 \mathrm{~b}$ production, macrophages levels, B-cell like and plasma-cell like amounts might explain the increased susceptibility to diseases occurring in chronic stress (Saeij et al., 2003; Small and Bilodeau, 2005; Mauri et al., 2011; Elenkov and Chrousos, 1999; Maule et al., 1989). Moreover, the improvement of CD4 mRNA amounts from 6 to $55 \%$ of control levels, which occurred between second and third weeks of chronic stress (Fig. 4C) may explain the recovery of inflammatory and regulatory functions at that time.

The IL17 PCR results (produced in Th17 cells) (Fig 3) suggest that its levels decline in acute and chronic stresses but increase towards the third week as seen in the case of CD4 elevation (Fig. 4C). This finding might reveal a recovery of the inflammatory functions in progressing chronic stress.

$\operatorname{IL1} \beta(\mathrm{p} \leq 0.05)$ and IL6 $(\mathrm{p} \leq 0.06)$ mRNA ratios which decreased during the second week of chronic stress, reached homeostasis at the third week, whereas, TNF $\alpha$ mRNA (Fig. 4A) remained stable along three weeks of stress. This result was slightly different from that reported for cortisol induced chronic stress in rainbow trout (Cortés et al., 2013), which showed that TNF $\alpha$ and IL1 $\beta$ increased after 5 days. That occurred in our study in the acute stress but not in the chronic stress. This 
contradiction might be due to differences in experimental conditions, i.e., the use of cortisol implants versus repeated air exposure. The unchanged levels of $\mathrm{TNF} \alpha$ and minor temporarily changes in IL1 $\beta$ and IL6 levels throughout the chronic stress (Fig. 4A), even though there was a drastic decrease in macrophages/monocytes, B-cells like, plasma-cells like (Table 2) and supposedly Th1 and NK cells, might point on additional stable proinflammatory resources. Moreover, the chemoattractant IL8 which was down-regulated along 22 days of the chronic stress (Fig. 4A) and did not relieve after the third week may explain the macrophage/neutrophil/leukocyte mobilization decline in different compartments of the body as shown by others (Wojtaszek et al., 2002).

FoxP3, known to be produced by regulatory cells (CD4 cells) decreased towards the second week before being elevated to homeostasis levels at the third week as also seen by the moderate elevation of CD4 mRNA (Fig. 4C and 4E).

Other regulatory cytokines, IL10 and TGF $\beta$ behaved in different ways throughout the stress period. While, IL10, was down-regulated throughout the three weeks of chronic stress and slightly rose at the third week $(p \leq 0.09)$, TGF $\beta$ showed considerable changes only at the second week of chronic stress and increased at the third week to homeostasis levels (Fig. 4E). This may indicate that regulatory functions may have different resources that respond in different ways to stress. In general, regulatory functions were indeed influenced by chronic stress but only for a while and eventually almost returned to homeostasis.

The increase of TGF $\beta$ together with IL6 mRNA at the third week may also explain the recovery of Th17 cells as indicated by the followed up-regulation of IL17 (Fig. 3) and CD4 mRNA (Fig 4C). IgM mRNA levels neither changed in acute stress nor in chronic stress in our experimental conditions (Table 3, Fig 3 and 4D). This result was in contradiction with husbandry, confinement or crowding induced stresses findings (Varsamos et al., 2006; Nagae et al., 1994; Maule et al., 1989; Rotllant et al., 1997; Ruane et al., 1999) and to the decrease in B-cell likes and plasma-cell likes (Table 2 and trend in Fig. 2), but in agreement with other studies (Douxfils et al., 2011; Cuesta et al., 2004; Vargas-Chacoff et al., 2014). These discrepancies were also shown in our lab as a result of pollution and temperature stress (not yet published) and it might be due to a presence of inhibitor controlling IgM humoral activity. Similarly, C3s mRNA showed no significant changes in both acute and chronic stresses, although its levels fluctuated throughout the chronic stress period (Fig. 3 and 4D). These results differ from the hemolytic findings of previous reports (Demers and Bayne, 1997; Sunyer and Tort, 1995; Mauri et al., 2011), but were in agreement with the reported hypoxia and cortisol induced stress (Douxfils et al., 2012; Eslamloo et al.,
2014). However, one cannot disregard that the measured plasma ACH50 which reported above (Demers and Bayne, 1997; Sunyer and Tort, 1995; Mauri et al., 2011) is based on the sum of the protein cascade in the complement activity and not solely on the C3s mRNA production. Therefore, it is likely that during stressful events complement protein variants, stress intensity and its duration, individual variations and the presence of inhibitors, represented a possible cause of these disagreements and fluctuations in $\mathrm{C} 3 \mathrm{~s}$ levels.

The involvement of some immune components in acute and chronic stresses, as discussed above, emphasizes which of these functions need further clarifications as follows: (1) The unchanged production in IgM and C3s mRNA levels in our study is not in agreement with the reported decrease in their activity in the blood (Varsamos et al., 2006; Nagae et al., 1994; Maule et al., 1989; Rotllant et al., 1997; Ruane et al., 1999; Demers and Bayne, 1997; Sunyer and Tort, 1995; Mauri et al., 2011). This discrepancy elicited the necessity to further clarify the existence of inhibitory functions during chronic stress. (2) Were the zero levels in IFN $\gamma 2 \mathrm{~b}$ and IL12b throughout chronic stress, due only to the impairment in monocytes, NK/Th1 and B cells? (3) The unchanged levels of TNFa and almost unchanged levels of IL1b and IL6, even after a decrease up to $80 \%$ in monocytes/macrophages levels, might enable the verification of the involved cellular mechanisms in the production of these cytokines during chronic stress. (4) We need to clarify the meaning of a persistent increase of PMN cell levels in the head kidney in trend tests $(\mathrm{p} \leq 0.05)$ (Fig. 2).

\section{Conclusion}

Based on the above findings, it can be concluded that:

- The decrease up to null in mRNA levels of IFN $\gamma 2 b$ and IL12b throughout chronic stress is probably due to the presence of an additional impaired population of cells, producing these cytokines, besides probable Th1 and/or NK cells

- The cells that were the most affected by chronic stress were macrophages, B-cell likes, plasma-cell likes and to a certain extent, the Th1 cells and subtypes of the NK cells/cytotoxic cells. This decline in these cells might explain the susceptibly to diseases during chronic stress

- The decrease in IL8 mRNA levels during chronic stress undoubtedly reduced leukocytes mobilization. As a result, the leukocyte recruitment at the affected sites might be injured

- The increase in pro-inflammatory and regulatory cytokines seems to counter balance temporary stresses but these cytokines stay almost unchanged throughout chronic stress 
- The levels of some constituents of innate immunity such as $\mathrm{C} 3 \mathrm{~s}$ and $\operatorname{IgM}$ mRNA were unchanged following acute and chronic stresses

\section{Acknowledgement}

The authors would like to thank Yuri Kaminer from Marine Lab for his assistance in all statistic tests, Ruti Segal from our lab for antibody production and Baruch and Yichiel from Mishmar HaSharon Fishery for donating the carp.

\section{Author's Contributions}

Mazal Shimon-Hophy: Planed and make all experiments, summarized the results and wrote the manuscript.

Ramy R. Avtalion: The idea of learning and ocmparing the effects of acute and chronic stresses in crap (Cyprinus carpio), an aninmal model currently used in our laboratory.

\section{Ethics}

This article is original and contains unpublished material. The corresponding author confirms that all of the other authors have read and approved the manuscript and no ethical issues involved.

\section{References}

Annunziato, F. and S. Romagnani, 2009. Heterogeneity of human effector $\mathrm{CD}^{+} \mathrm{T}$ cells. Arthritis Res. Ther., 11: 257-264. DOI: 10.1186/ar2843

Avtalion, R.R., 1969. Temperature effect on antibody production and immunological memory, in carp (Cyprinus carpio) immunized against Bovine Serum Albumin (BSA). Immunology, 17: 927-931. PMID: 5386638

Avtalion, R.R., 1981. Environmental control of the immune response in fish. CRC. Crit. Rev. Environ. Control., 11: 163-188.

DOI: $10.1080 / 10643388109381687$

Avtalion, R.R., E. Weiss and T. Moalem, 1976. Regulatory Effects of Temperature Upon Immunity in Ectothermic Vertebrates. In: Comperative Immunology, Marchalonis, J.J. (Ed.), Blackwell Edit, Oxford, p: 227-238.

Banerjee, S. and M. Leptin, 2014. Systemic response to ultraviolet radiation involves induction of leukocytic IL-1 $\beta$ and inflammation in zebrafish. J. Immunol., 193: 1408-1415. DOI: $10.4049 /$ jimmunol.1400232

Barker, J.N., R.S. Mitra, C.E. Griffiths, V.M. Dixit and B.J. Nickoloff, 1991. Keratinocytes as initiators of inflammation. Lancet, 337: 211-214. DOI: $10.1016 / 0140-6736(91) 92168-2$
Brattgjerd, S and O. Evensen, 1996. A sequential light microscopic and ultrastructural study on the uptake and handling of Vibrio salmonicida in phagocytes of the head kidney in experimentally infected Atlantic salmon (Salmo salar L.). Vet Pathol., 33: 55-65. DOI: $10.1177 / 030098589603300106$

Campbell, P.M., T.G. Pottinger and J.P. Sumpter, 1992. Stress reduces the quality of gametes produced by rainbow trout. Biol. Reprod., 47: 1140-1150. DOI: $10.1095 /$ biolreprod47.6.1140

Cortés, R., M. Teles, R. Trídico, L. Acerete and L. Tort, 2013. Effects of cortisol administered through Slow-Release Implants on Innate Immune Responses in rainbow trout (Oncorhynchus mykiss). Inter. J. Gen., 2013: 619714-619720. DOI: 10.1155/2013/619714

Costas, B., L.E.C. Conceição, J. Dias, B. Novoa and A. Figueras et al., 2011. Dietary arginine and repeated handling increase disease resistance and modulate innate immune mechanisms of Senegalese sole (Solea senegalensis Kaup, 1858). Fish Shellfish Immunol., 31: 838-847. DOI: $10.1016 /$ j.fsi.2011.07.024

Cristea, V., M. Mocanu, A. Antache, A. Docan and L. Dediu et al., 2012. Effect of stocking density on leukocyte reaction of Oncorhynchus mykiss (Walbaum, 1792). Anim. Sci. Biotechnol., 45: 31-36.

Cuesta, A., J. Meseguer and M.A. Esteban, 2004. Total serum immunoglobulin $M$ levels are affected by immunomodulators in seabream (Sparus aurata L.). Vet. Immunol. Immunopathol., 101: 203-210. DOI: $10.1016 /$ j.vetimm.2004.04.021

Demers, N.E. and C.J. Bayne, 1997. The immediate effects of stress on hormones and plasma lysozyme in rainbow trout. Dev. Comp. Immunol., 21: 363-373. DOI: $10.1016 / \mathrm{S} 0145-305 \mathrm{X}(97) 00009-8$

Dhabhar, F.S., 2002. Stress-induced augmentation of immune function-the role of stress hormones, leukocyte trafficking and cytokines. Brain Behav. Immun., 16: 785-798. DOI: 10.1016/S0889-1591(02)00036-3

Douxfils, J., C. Mathieu, S.N. Mandiki, S. Milla and E. Henrotte et al., 2011. Physiological and proteomic evidences that domestication process differentially modulates the immune status of juvenile Eurasian perch (Perca fluviatilis) under chronic confinement stress. Fish Shellfish Immunol., 31: 1113-1121. DOI: 10.1016/j.fsi.2011.10.001

Douxfils, J., M. Deprez, S.N.M. Mandiki, S. Milla and E. Henrotte et al., 2012. Physiological and proteomic responses to single and repeated hypoxia in juvenile Eurasian perch under domesticationClues to physiological acclimation and humoral immune modulations. Fish Shellfish Immunol., 33: 1112-1122. DOI: 10.1016/j.fsi.2012.08.013 
Dror, M., MS. Sinyakov, E. Okun, M. Dym and B. Sredni et al., 2006. Experimental handling stress as infection-facilitating factor for the goldfish ulcerative disease. Vet. Immunol. Immunopathol., 109: 279-287. DOI: 10.1016/j.vetimm.2005.08.022

Du, L., L. Qin, X. Wang, A. Zhang and H. Wei et al., 2014. Characterization of grass carp (Ctenopharyngodon idella) IL-17D: Molecular cloning, functional implication and signal transduction. Dev. Comp. Immunol., 42: 220-228. DOI: $10.1016 /$ j.dci.2013.09.015

Elenkov, I.J. and G.P. Chrousos, 1999. Stress hormones, Th1/Th2 patterns, pro/anti-inflammatory cytokines and susceptibility to disease. Trends Endocrinol. Metab., 10: 359-368.

DOI: $10.1016 / \mathrm{S} 1043-2760(99) 00188-5$

Engelsma, M.Y., S. Hougee, D. Nap, M. Hofenk and J.H. Rombout et al., 2003. Multiple acute temperature stress affects leucocyte populations and antibody responses in common carp, Cyprinus carpio L. Fish Shellfish Immunol., 15: 397-410. DOI: $10.1016 / \mathrm{S} 1050-4648(03) 00006-8$ 10.1016/S1050-4648(03)00006-8

Eslamloo, K., S.R. Akhavan, F.J. Fallah and M.A. Henry, 2014. Variations of physiological and innate immunological responses in goldfish (Carassius auratus) subjected to recurrent acute stress. Fish Shellfish Immunology, 37: 147-153.

DOI: $10.1016 /$ j.fsi.2014.01.014

Franco, R., R. Sanchez-Olea, E.M. Reyes-Reyes and M.I. Panayiotidis, 2009. Environmental toxicity, oxidative stress and apoptosis: Ménage à Trois. Mutat. Res., 674: 3-22.

DOI: 10.1016/j.mrgentox.2008.11.012

Harmon, T.S., 2009. Methods for reducing stressors and maintaining water quality associated with live fish transport in tanks: A review of the basics. Rev. Aquacul., 1: 58-66. DOI: $10.1111 / \mathrm{j} .1753-5131.2008 .01003 . \mathrm{x}$

Harper, C. and J.C. Wolf, 2009. Morphologic effects of the stress response in Fish. ILAR J., 50: 387-396. DOI: 10.1093/ilar.50.4.387

Harris, J. and D.J. Bird, 2000. Modulation of the fish immune system by hormones. Vet. Immunol. Immunopathol., 77: 163-176. DOI: $10.1016 / \mathrm{S} 0165-2427(00) 00235-\mathrm{X}$

Hoskonen, P. and J. Pirhonen, 2006. Effects of repeated handling, with or without anaesthesia, on feed intake and growth in juvenile rainbow trout, Oncorhynchus mykiss (Walbaum). Aquacul. Res., 37: 409-415. DOI: $10.1111 /$ j.1365-2109.2005.01448.x

Kaattari, S.L. and M.J. Irwin, 1985. Salmonid spleen and anterior kidney harbor populations of lymphocytes with different $\mathrm{B}$ cell repertoires. Dev. Comp. Immunol., 9: 433-44.

DOI: $10.1016 / 0145-305 \times(85) 90006-0$
Kohli, G., S. Hu, E. Clelland, T. Di Muccio and J. Rothenstein et al., 2003. Cloning of transforming growth factor- $\beta 1$ (TGF- $\beta 1$ ) and its type II receptor from zebrafish ovary and role of TGF- $\beta 1$ in Oocyte maturation. Endocrinology, 144: 1931-1941. DOI: $10.1210 /$ en.2002-0126

Law, W.Y., W.H. Chen, Y.L. Song, S. Dufour and C.F. Chang, 2001. Differential in vitro suppressive effects of steroids on leukocyte phagocytosis in two teleosts, tilapia and common carp. Gen. Comp. Endocrinol., 121: 163-172. DOI: $10.1006 /$ gcen.2000.7593

Lefèvre, F., J. Bugeon, B. Aupérin and J. Aubin, 2008. Rearing oxygen level and slaughter stress effects on rainbow trout flesh quality. Aquaculture, 284: 81-89. DOI: 10.1016/j.aquaculture.2008.07.017

Livak, K.J. and T.D. Schmittgen, 2008. Analyzing realtime PCR data by the comparative $\mathrm{C}_{\mathrm{T}}$ method. Nat. Protocols, 3: 1101-1108. DOI: $10.1038 /$ nprot.2008.73

Maule, A.G. and C.B. Schreck, 1991. Stress and cortisol treatment changed affinity and number of glucocorticoid receptors in leukocytes and gill of coho salmon. Gen. Comp. Endocrinol., 84: 83-93. DOI: 10.1016/0016-6480(91)90067-G

Maule, A.G., R.A. Tripp, S.L. Kaattari and C.B. Schreck, 1989. Stress alters immune function and disease resistance in chinook salmon (Oncorhynchus tshawytscha). J Endocrinol., 120: 135-142. DOI: $10.1677 /$ joe. 0.1200135

Mauri, I., A. Romero, L. Acerete, S. MacKenzie and N. Roher et al., 2011. Changes in complement responses in Gilthead seabream (Sparus aurata) and European seabass (Dicentrarchus labrax) under crowding stress, plus viral and bacterial challenges. Fish Shellfish Immunol., 30: 182-188. DOI: $10.1016 /$ j.fsi.2010.10.006

Melamed, O., B. Timan, R.R. Avtalion and E.G. Noga, 1999. Design of a stress model in the hybrid bass (Morone Saxatilis X Morone Crysops). Isr. J. Aquacult., 51: 10-16.

Milla, S., C. Mathieu, N. Wang, S. Lambert and S. Nadzialek et al., 2010, Spleen immune status is affected after acute handling stress but not regulated by cortisol in Eurasian perch, Perca fluviatilis. Fish Shellfish Immunol., 28: 931-941. DOI: $10.1016 /$ j.fsi.2010.02.012

Mommsen, T.P., M.M. Vijayan and T.W. Moon, 1999. Cortisol in teleosts: Dynamics, mechanisms of action and metabolic regulation. Rev. Fish Biol. Fish, 9: 211-268. DOI: 10.1023/A:1008924418720

Montero, D., L. Tort, L. Robaina, J.M. Vergara and M.S. Izquierdo, 2001. Low vitamin $\mathrm{E}$ in diet reduces stress resistance of gilthead seabream (Sparus aurata) juveniles. Fish Shellfish Immunol., 11: 473-490. DOI: 10.1006/fsim.2000.0324 
Montero, D., M. Marrero, M.S. Izquierdo, L. Robaina and J.M. Vegara et al., 1999. Effect of vitamin E and C dietary supplementation on some immune parameters of gilthead seabream (Sparus aurata) juveniles subjected to crowding stress. Aquaculture, 171: 269-278. DOI: 10.1016/S0044-8486(98)00387-1

Nagae, M., H. Fuda, K. Ura, H. Kawamura and S. Adachi et al., 1994. The effect of cortisol administration on blood plasma immunoglobulin $\mathrm{M}$ (IgM) concentrations in masu salmon (Oncorhynchus masou). Fish Physiol. Biochem., 13: 41-48. DOI: 10.1007/BF00004118

Nakao, M., J. Mutsuro, R. Obo, K. Fujiki and M. Nonakaand et al., 2000. Molecular cloning and protein analysis of divergent forms of the complement component $\mathrm{C} 3$ from a bony fish, the common carp (Cyprinus carpio): Presence of variants lacking the catalytic histidine. Eur. J. Immunol., 30: 858-866.

DOI: $\quad 10.1002 / 1521-4141(200003) 30: 3<858:: A I D-$ IMMU858>3.0.CO;2-M

Nardocci, G., C. Navarro, P.P. Cortes, M. Imarai and M. Montoya et al., 2014. Neuroendocrine mechanisms for immune system regulation during stress in fish. Fish Shellfish Immunol., 40: 531-538.

DOI: 10.1016/j.fsi.2014.08.001

Noga, E.J., C.J. Wang, C.B. Grindem and R.R. Avtalion, 1999. Comparative clinicopathological responses of striped bass and palmetto bass to acute stress. Trans. Amer. Fish. Soc., 128: 680-686. DOI: 10.1577/15488659(1999) $128<0680$ :CCROSB $>2.0$. CO; 2

Olsen, R.E., K. Sundell, T.M. Mayhew, R. Myklebust and E. Ringo, 2005. Acute stress alters intestinal function of rainbow trout, Oncorhynchus mykiss (Walbaum). Aquaculture, 250: 480-495.

DOI: $10.1016 /$ j.aquaculture.2005.03.014

Øverli, Ø., C. Sørensen, A. Kiessling, T.G. Pottinger and H.M. Gjøen, 2006. Selection for improved stress tolerance in rainbow trout (Oncorhynchus mykiss) leads to reduced feed waste. Aquaculture, 261: 776-781. DOI: 10.1016/j.aquaculture.2006.08.049

Petrovsky, N., 2001. Towards a unified model of neuroendocrine-immune interaction. Immunol. Cell Biol., 79: 350-357.

DOI: $10.1046 /$ j.1440-1711.2001.01029.x

Pfaffl, M.W., 2001. A new mathematical model for relative quantification in real-time RT-PCR. Nucleic Acids Res., 29: 2002-2007. DOI: $10.1093 /$ nar/29.9.e45

Pickering, A.D., 1984, Cortisol-induced lymphocytopenia in brown trout, Salmo trutta. Gen. Comp. Endocrinol., 53: 252-259. DOI: 10.1016/0016-6480(84)90250-8

Pickering, A.D., 1992. Rainbow trout husbandry: Management of the stress response. Aquaculture, 100: 125-139. DOI: 10.1016/0044-8486(92)90354-N
Poli, B.M., G. Parisi, F. Scappini and G. Zampacavallo, 2005. Fish welfare and quality as affected by preslaughter and slaughter management. Aquacult. Internat., 13: 29-49.

DOI: $10.1007 / \mathrm{s} 10499-004-9035-1$

Pulsford, A.L., M. Crampe, A. Langston and P.J. Glynn, 1995. Modulatory effects of disease, stress, copper, TBT and vitamin $E$ on the immune system of flatfish. Fish Shellfish Immunol., 5: 631-643. DOI: $10.1016 / \mathrm{S} 1050-4648(95) 80046-8$

Raberg, L., M. Grahn, D. Hasselquist and E. Svensson, 1998. On the adaptive significance of stress-induced immunosuppression. Proc. Biol. Sci., 265: 1637-1641. DOI: 10.1098/rspb.1998.0482

Rotllant, J., M. Pavlidis, M. Kentouri, M.E. Abad and L. Tort, 1997. Non-specific immune responses in the red porgy Pagrus pagrus after crowding stress. Aquaculture, 156: 279-290.

DOI: $10.1016 / \mathrm{S} 0044-8486(97) 00075-6$

Ruane, N.M., S.E. Wendelaar Bonga and P. Balm, 1999. Differences between rainbow trout and brown trout in the regulation of the pituitaryinterrenal axis and physiological performance during confinement. Gen. Comp. Endocrinol., 115: 210-219. DOI: 10.1006/gcen.1999.7292

Saeij, J.P., L.B. Verburg-van Kemenade, W.B. van Muiswinkel and G.F. Wiegertjes, 2003. Daily handling stress reduces resistance of carp to Trypanoplasma borreli: in vitro modulatory effects of cortisol on leukocyte function and apoptosis. Dev. Comp. Immunol., 27: 233-245. DOI: $10.1016 / \mathrm{S} 0145-305 \mathrm{X}(02) 00093-9$

Secombes, C.J. and T.C. Fletcher, 1992. The role of phagocytes in the protective mechanisms of fish. Annual Rev. Fish Disease, 2: 53-71. DOI: 10.1016/0959-8030(92)90056-4

Small, B.C. and A.L. Bilodeau, 2005. Effects of cortisol and stress on Channel Catfish (Ictalurus punctatus) pathogen susceptibility and lysozyme activity following exposure to Edwardsiella ictaluri. Gen. Comp. Endocrinol., 142: 256-262. DOI: $10.1016 /$ j.ygcen.2004.12.004

Sunyer, J.O. and L. Tort, 1995. Natural hemolytic and bactericidal activities of sea bream Sparus aurata serum are effected by the alternative complement pathway. Vet. Immunol. Immunopathol., 45: 333-345. DOI: 10.1016/0165-2427(94)05430-Z

Talbot, A.T., T.G. Pottinger, T.J. Smith and M.T. Cairns, 2009. Acute phase gene expression in rainbow trout (Oncorhynchus mykiss) after exposure to a confinement stressor: A comparison of pooled and individual data. Fish Shellfish Immunol., 27: 309-317. DOI: $10.1016 /$ j.fsi.2009.05.016 
Todaa, H., Y. Saitoa, T. Koikea, F. Takizawaa and K. Arakib et al., 2011. Conservation of characteristics and functions of CD4 positive lymphocytes in a teleost fish. Dev. Com. Immunol., 35: 650-660. DOI: $10.1016 /$ j.dci.2011.01.013

Tort, L., 2011. Stress and immune modulation in fish. Dev Comp. Immunol., 35: 1366-1375. DOI: 10.1016/j.dci.2011.07.002

Tort, L., J.O. Sunyer, E. Gómez and A. Molinero, 1996. Crowding stress induces changes in serum haemolytic and agglutinating activity in the gilthead sea bream Sparus aurata. Vet. Immunol. Immunopathol., 51: 179-188. DOI: 10.1016/0165-2427(95)05502-9

Van der Aa, L.M., M. Chadzinska, L.A. Golbach, C.M.S. Ribeiro and B.M.L. Verburg-van Kemenade, 2012. Pro-inflammatory functions of carp CXCL8-like and $\mathrm{CXCb}$ chemokines. Dev. Comparative Immunol., 36: 741-750. DOI: 10.1016/j.dci.2011.11.011

Vargas-Chacoff, L., A. Calvo, I. Ruiz-Jarabo, F. Villarroel and J.L. Mũnoz et al., 2011. Growth performance, osmoregulatory and metabolic modifications in red porgy fry, Pagrus pagrus, under different environmental salinities and stocking densities. Aquacult. Res., 42: 1269-1278. DOI: $10.1111 / \mathrm{j} .1365-2109.2010 .02715 . \mathrm{x}$

Vargas-Chacoff, L., D. Martínez, R. Oyarzún, D. Nualart and V. Olavarría et al., 2014. Combined effects of high stocking density and Piscirickettsia salmonis treatment on the immune system, metabolism and osmoregulatory responses of the Sub-Antarctic Notothenioid fish Eleginops maclovinus. Fish Shellfish Immunol., 40: 424-434.

DOI: 10.1016/j.fsi.2014.07.024

Varsamos, S., G. Flik, J.F. Pepin, S.E. Bonga and G. Breuil, 2006. Husbandry stress during early life stages affects the stress response and health status of juvenile sea bass, Dicentrarchus labrax. Fish Shellfish Immunol., 20: 83-96. DOI: 10.1016/j.fsi.2005.04.005

Vazzana, M., M. Cammarata, E.L. Cooper and N. Parrinello, 2002. Confinement stress in sea bass (Dicentrarchus labrax) depresses peritoneal leukocyte cytotoxicity. Aquaculture, 210: 231-243. DOI: 10.1016/S0044-8486(01)00818-3

Verburg-Van Kemenade, B.M.L., B. Nowak, M.Y. Engelsma and F.A.A. Weyts, 1999. Differential effects of cortisol on apoptosis and proliferation of carp B-lymphocytes from head kidney, spleen and blood. Fish Shellfish Immunol., 9: 405-415.

DOI: $10.1006 /$ fsim. 1998.0197

Verburg-Van Kemenade, B.M.L., E.H. Stolte, J. Metz and M. Chadzinska, 2009. Neuroendocrine-Immune Interactions in Teleost Fish. In: Fish Physiology: Fish Neuroendocrinology, Bernier, N.J., G. van Der Kraak, A.P. Farreli and C.J. Brauner (Eds.), Academic Press-Elsevier, London, UK, San Diego, Ca, USA., p: 313-364.
Wan, Y.Y. and R.A. Flavell, 2009. How diverse-CD4 effector $\mathrm{T}$ cells and their functions. J. Mol. Cell Biol., 1: 20-36. DOI: 10.1093/jmcb/mjp001

Wang, T., M. Husain, S. Hong and J.M. Holland, 2014. Differential expression, modulation and bioactivity of distinct fish IL-12 isoforms: Implication towards the evolution of Th1-like immune responses. Eur. J. Immunol., 44: 1541-1551. DOI: $10.1002 /$ eji.201344273

Wang, T., M.M. Monte, W. Huanga, P. Boudinot and S.A.M. Martin et al., 2010. Identification of two FoxP3 genes in rainbow trout (Oncorhynchus mykiss) with differential induction patterns. Mol. Immunol., 47: 2563-2574.

DOI: $10.1016 /$ j.molimm.2010.06.015

Wei, H., M. Yang, T. Zhao, X. Wang and H. Zhou, 2013. Functional expression and characterization of grass carp IL-10: An essential mediator of TGF- $\beta 1$ immune regulation in peripheral blood lymphocytes. Mol. Immunol., 53: 313-320.

DOI: 10.1016/j.molimm.2012.08.021

WendelaarBonga, S.E., 1997. The stress response in fish. Physiol. Rev., 77: 591-625. PMID: 9234959

Wojtaszek, J., D. Dziewulska-Szwajkowska, M. Lozinska-Gabska, A. Adamowicz and A. Dzugaj, 2002. Hematological effects of high dose of cortisol on the carp (Cyprinus carpio L.): Cortisol effect on the carp blood. Gen. Comp. Endocrinol., 125: 176-183. DOI: $10.1006 /$ gcen.2001.7725

Zarate, J. and T.M. Bradley, 2003. Heat shock proteins are not sensitive indicators of hatchery stress in salmon. Aquaculture, 223: 175-187. DOI: $10.1016 / \mathrm{S} 0044-8486(03) 00160-1$

Zou, J., A. Carrington, B. Collet, J.M. Dijkstra and Y. Yoshiura et al., 2005. Identification and bioactivities of IFN- $\gamma$ in Rainbow Trout Oncorhynchus mykiss: The First Th1-Type cytokine characterized functionally in Fish. J. Immunol., 175: 2484-2494. DOI: $10.4049 /$ jimmunol.175.4.2484 